\title{
Street Vending Power Relationships and Governance of Public Spaces in Bafoussam, West Cameroon
}

\author{
Aristide Yemmafouo \\ Department of Geography, University of Dschang, Dschang, Cameroon \\ Email: ayemmafouo@yahoo.fr
}

How to cite this paper: Yemmafouo, A. (2018). Street Vending Power Relationships and Governance of Public Spaces in Bafoussam, West Cameroon. Current Urban Studies, 6, 611-629.

https://doi.org/10.4236/cus.2018.64032

Received: November 16, 2018

Accepted: December 26, 2018

Published: December 29, 2018

Copyright (C) 2018 by author and Scientific Research Publishing Inc. This work is licensed under the Creative Commons Attribution International License (CC BY 4.0).

http://creativecommons.org/licenses/by/4.0/

(c) (i) Open Access

\begin{abstract}
Street vending has a strong and latent structuring power, supported by distribution networks which exploit informal economies. It is regarded as a terminal of a massive supply of goods and their commercialisation in Southern Cities. Intermediate cities such as Bafoussam, animating dynamic peripheries have an economic fabric which is strongly supported by informal economies. These cities seek to regulate informal trade in order to mitigate unemployment impact while generating income. The target of this article is to show how power relationship building by street vending impacts the governance of public spaces. It is hypothesised that at the grassroots level of the network of urban economic fabric in medium-sized cities, the tolerance of street vending as a governance model has become a power sharing with Vendors. 35 in-depth interviews and three focus group discussions were conducted with vendors along Market A and Market B road that spans over 10 kilometres. This was to understand the strategies that govern the occupation and functioning of street vending, the network relationships it displays and the implications on governance of public spaces. The importance of street vending and the networks it shapes in Bafoussam gives it a power that ensures its long-term presence on public spaces, urban economic and socio-political stability.
\end{abstract}

\section{Keywords}

Street Vending Diversity, Street Vendors Networks, Power Relationship, Power Sharing, Governance of Public Spaces, Cameroon

\section{Introduction}

Street vending is a terminal of mass distribution for an actual satisfaction of un- 
derprivileged people in Southern Cities, a multifarious set of profitable activities, staged on public spaces so as to magnetise its major spatial characteristic. In medium-sized Cities ranging from 100,000 to 500,000 inhabitants (Lamblin \& Massot, 2011) structuring regional development such as Bafoussam, the informal sector shapes the fledgling economic fabric and organises the City-Rural relationships in connection with the national metropolises, Douala and Yaounde. Street vending has a strong regenerating capacity of its actors. Nevertheless, instead of being a transitive situation, it is a perennial activity strengthening a street power investigated through the following question: How does power relationships derived from street vending development affect the governance of public spaces in medium-sized Cities? In fact, beautification operations through evictions of people have shown poor results (Assako, 2012).

The economy of medium-sized Cities in Cameroon is predominantly informal and imposes adapted approaches which are mostly more experienced in East Africa (Brown et al., 2010; Schlegel \& Racaud, 2016). Urban disorder expresses any unpredictable deviation from urban planning agenda. It illustrates major dysfunctions in the socio-spatial and landscape organisation of urban space (Sampson, 2009; Indovina, 2016). This is associated with antisocial behaviour, poor infrastructure maintenance and the unsightly nature of the urban landscape. The fight against urban disorder has become a paramount concern in Cameroon since the country regained economic growth.

Street vending firstly developed as a timely strategy for survival and for bringing goods closer to consumers. It was then consolidated as an extension of market and finally as a perennial activity shaping urban economy and life in town. Despite the effectiveness of some mass distribution shops, it is difficult to escape street products in small and medium-sized Cities, since this is sometimes the only means of mass distribution. This necessity for street vending remains poorly perceived by decisions-makers of African Cities (Brown et al., 2010). This study seeks to analyse the power relationship building by street vending and its impact on the governance of public spaces. It shows that the informal economy materialised by street vending meets an urban demand and is integrated into the urban economic system which makes it the major actor concerned in the governance of public spaces. It is hypothesised that at the grassroots level of the network of urban economic fabric in medium-sized Cities, the tolerance of street vending as a governance model has become a share of power with Public Authorities.

A number of researchers have documented the structure and function of street vending especially in Latin American Cities (Staudt, 1996; Cross, 1998; Bromley, 2000; Monnet, 2006). It has been identified three dimensions of street vending (Monnet, 2006) which will help to structure the analysis of this paper. Firstly, the legal and economic dimension together with the informal nature of activities (i.e., propensity for tax evasion and smuggling), hinders the integration into the local account. This has resulted in the poor nature of relationships with 
city managers, their suppliers and customers. Street vending's informal nature does not exempt vendors from paying taxes and their conformity with the rules of trade, which includes the quality of both the product and the commercial space. This is what Monnet called "interstices of the formality". Secondly, the spatial dimension takes into consideration not only the public space, but also the commercial private property adjacent to the road. This is due to the fact that the street is subject to a geographical study from which we do question the quality of goods and services provided, the layering of inequalities, and the power relationships going on up to formalised levels (Augustin, 2002; Fleury, 2004; Steck, 2006). The targeted spatial dimension does not only encompasses roads connecting myriads of urban areas, but rather the commercial activities that take place in this space as well as the power relationships, which emerge from them. The concept of public space refers to the geographical dimension of areas where city retailers settle on all types of streets, squares, gardens, freely accessible and protected by the society and the law. It is a social space where anonymity, posting, rites, adventures and many socialisations intertwine (Augustin, 2002). Vendors' common sense, intelligence and pragmatism stand as inspirations guiding them strategically settle where accessibility to potential customers is topmost. The first ones getting settled make sure that they do have the rights of occupancy. This legitimacy allows them not to admit others join them at wish. Consequently, the popular saying stating that the land belongs to the first occupants prevails here and then power relationships hatch convenient governance issues regulating the rights of occupancy of newly settled vendors in the public space. Thirdly, the mobility dimension depicts the itinerant nature of the activity as vendors could express the wish to move promptly when the need arises. Therefore, fixed supports and stands are street vendors' signposts, a wisely designed code of advertisement captions for customers and passers-by to glance at their display. The "interstices of mobility" (Monnet, 2006) also refers to the moment of mobility favourable to customers, whether on their travel paths, at bus stations or at junctions.

This Monnet's framework is completed with Brooks's (2012), using Global Production Network (GPN) to map and understand power relationships structuring a street product. Brooks (2012) uses the said approach to investigate the international second-hand clothing trade, taking Mozambique as the end node of distribution. Despite the plurality of their scales of analysis, GPN approaches (Henderson et al., 2002; Coe et al., 2008) permit to underline the embeddedness of "different actors within societies and territories" (Brooks, 2012: p. 2) and logically call to closely study contested spaces and power sharing as proposed by Brown (2006). Street vending being a terminal of mass distribution for underprivileged people in Southern Cities, structures a local power relationship which is linked to GPN.

The last slot of this paper focuses on the fieldwork, presentation and discussion of results. The findings explore the diversity of the street vending, the actors 
and power relationship building and sharing in the governance of public spaces. The discussion explores the pertinence of Monnet's and Brooks's framework to tackle street vendors' power relationship implications within the global-local scope.

\section{Fieldwork}

Bafoussam is the third largest city in Cameroon after Douala and Yaounde metropolises. With more than 300,000 inhabitants, the city heads the 31 towns of the West Region's urban network. This Region is classified among the most densely populated areas of Cameroon $\left(400 \mathrm{inhab} / \mathrm{km}^{2}\right)$, and villages and towns are closely linked by the exchange of products especially by the vitality of direct relationships with metropolises (Figure 1). Bafoussam therefore, maintains a growth rate of $4.1 \%$ (1987-2005) through commercial activities due to its position of headquarters of the Region and that of intermediary centrality between the metropolises and countryside. These activities, mostly informal, characterise the urban landscape. The main roads are subject to competition for the establishment of commercial activities.

A qualitative empirical approach was adopted for this study. After observing street vending, a systematic survey was carried out along the main road of Bafoussam. This road crosses the two major markets of the city (Markets A and B) and extends to about $10 \mathrm{~km}$ with a diversity of street vending activities. We conducted 35 in-depth interviews (30 - 90 mins each) with vendors and services providers located on this street. The street was divided into homogeneous

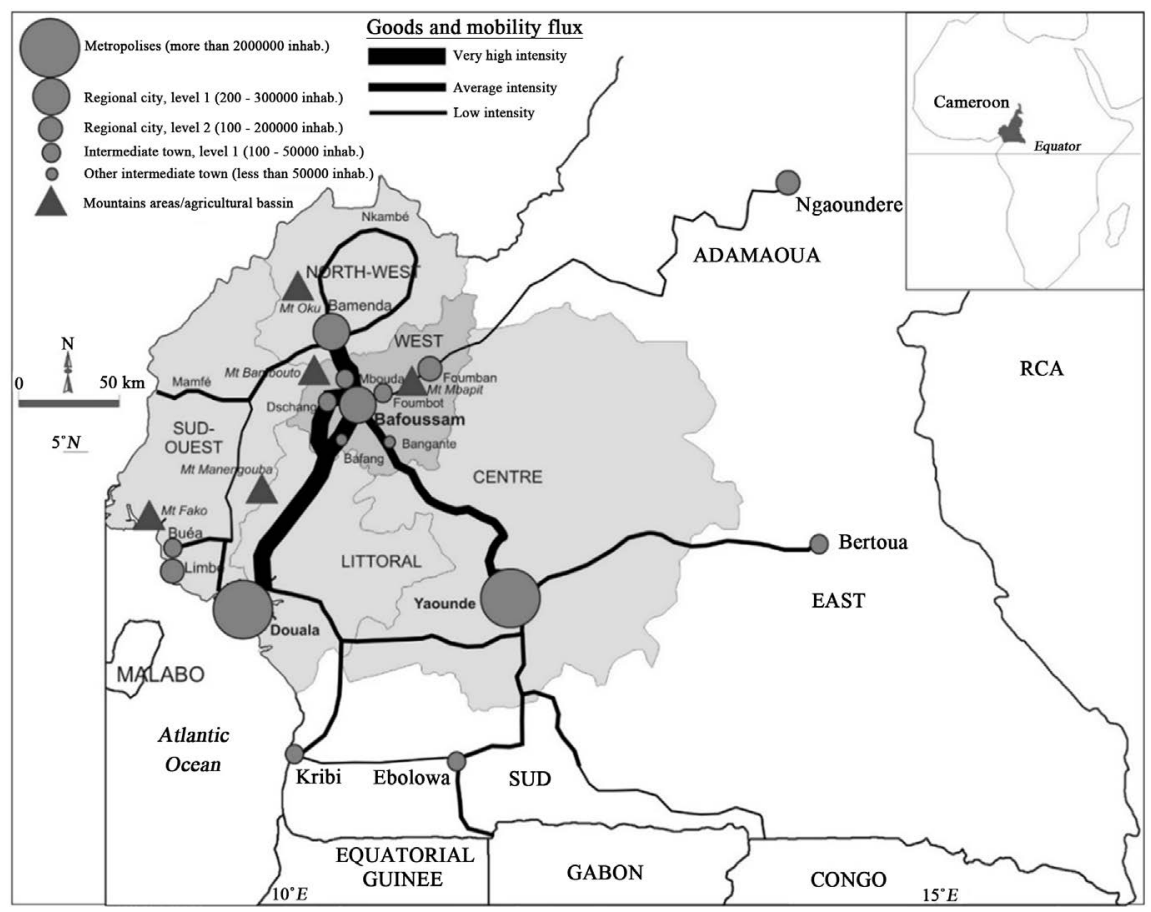

Figure 1. Bafoussam and its relationships. Source: Author, 2017, from administrative Map of Cameroon. 
segments according to the dominant activity. Thus, 11 segments were constituted for at least three interviews per segments (Figure 2). Furthermore, three focus group discussions were conducted for about an hour. The first focus group was composed of vendors who occupied the public space along the Market B road. The second with vendors around Douala-Yaounde Bus Station and the last interview was conducted with the cooperation of Municipal Agents involved in the fight against urban disorder. It was not necessary to distinguish men from women in the focus group as we did not notice any particular gender differences. Interviews and focus group discussions were recorded and transcribed into text before being manually analysed. Overall, 1839 activities were identified and classified into nine categories (Figure 2).

\section{Street Vending Diversity in Bafoussam}

The diversity of street vending according to Monnet (2006: p. 97) is organised within a triangle formed by informality, mobility and spatiality. Within the triangle, there are four transaction zones: informal and hawker (e.g. vendors beside traffic lights), non-hawker but informal transaction (e.g. Unauthorised kiosk), hawker and authorised (e.g. newspapers and airtime vendors) and informal and hawker zone out of public spaces (e.g. inside buses and restaurants). However, vendors have reference zones, which are real territories where they have their bearings, their codes and their emergency exits. Semi-mobile ones have an activity radius of $500 \mathrm{~m}-1 \mathrm{~km}$ at most. In reality, they are fixed on mobile platforms where they easily escape council controls, as they pretend to be mobile. Depending on the nature of the activity, Roever (2014) distinguishes buy-sell, which may correspond to the Cameroonian Buyam-Sellam. Transformations such as catering, sewing and carpentry for example offer direct consumable products to users. These services satisfy other immediate needs such as airtime selling and secretariat works among others.

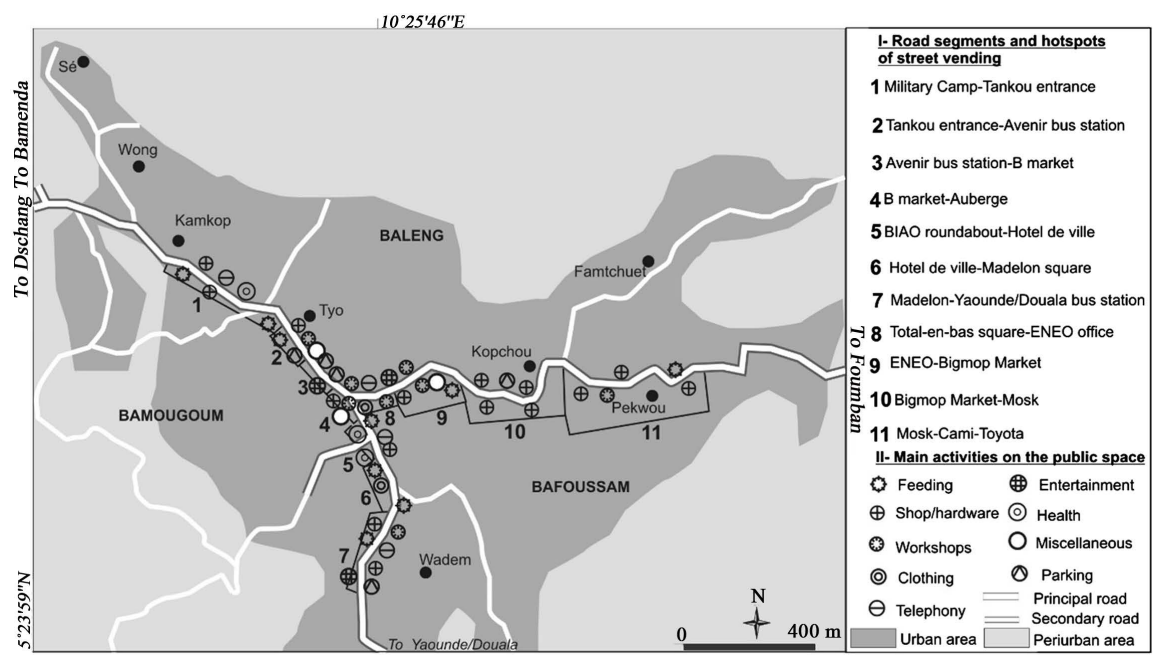

Figure 2. Spatial distribution of activities on the public space of the Bafoussam main road. Source: Author, 2017, from Bafoussam Map. 
Street food is a popular catering found in African Cities (Mitullah, 2003; Etoughe-Efe, 2010; Sohel et al., 2015; Githiri et al., 2016). Mostly known under the term tournedos in Cameroon, these baroque restaurants are appreciated for their geographical, social and economic accessibility despite their doubtful hygienic conditions. Handicraft includes services and diverse tools for manufacturing such as building materials, carpentry, welding, repairers and wheel bonding. These shops are located out of public spaces where operations take place. The arrival of mobile telephones has given rise to the creation of a series of street activities among which are call boxes with associating activities and stalls of basic needs (Figure 3).

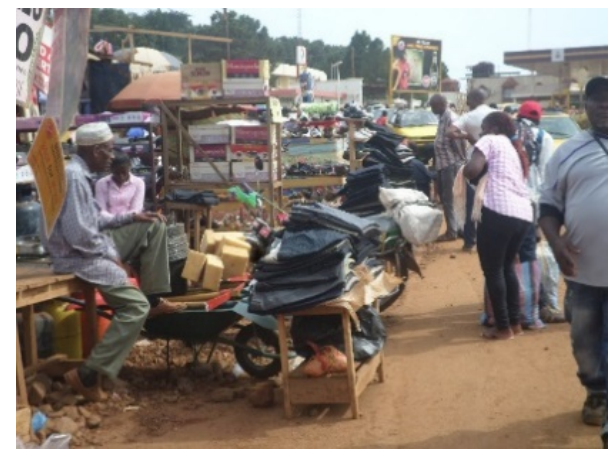

(a)

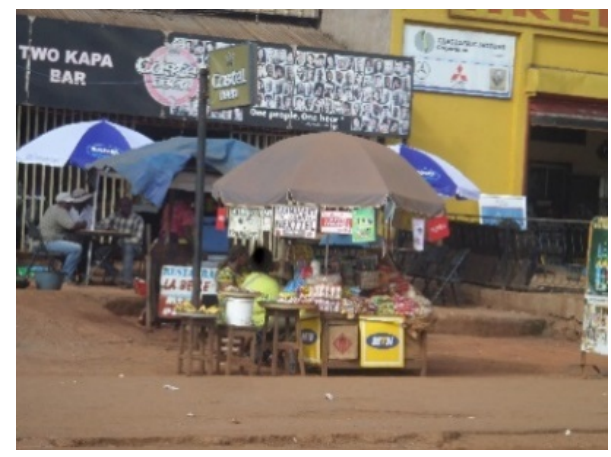

(b)

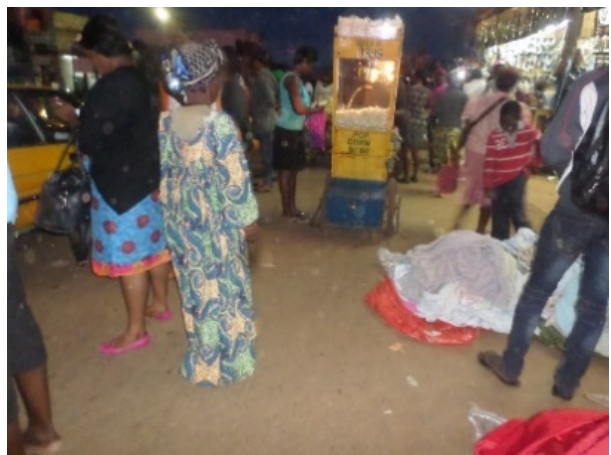

(c)

Figure 3. Vending scenes along commercial avenue in Bafoussam. (a) Second hand clothes in open air; (b) Stalls "a bit of everything" near a bar; (c) Street vending in the night: Second hand clothes, Pop Corn, etc. till 10 pm. Sources: Author, April 2017. 
Services offered in the street are essentially on precarious support. $36.12 \%$ (389) of products are displayed on tables or stalls with at most $1.5 \mathrm{~m}$ height from the ground. $20.98 \%$ (226) are offered by hardware shops and bars whereas $15.23 \%$ (164) are workshops installed on public spaces adjacent to the street. 9.75\% (105) of products are displayed on the ground, 7.89\% (85) in kiosks, $4.92 \%$ (53) in trucks and wheelbarrows. It can be argued that the density of street vending activities is correlated to the CBD borders, which is the main market place. Hot points of street vending are therefore located at BIAO Roundabout and Total d'en bas Junction. Other hot points are located at the main junction and entrance of residential settlements. Street vending is a proximity distribution of a wide variety of basic products and services. Vendors must have important connections with suppliers as well as with the administrative authorities or important personalities at the local or national level.

\section{Actors and Power Relationships Building}

\subsection{Underemployed Young People with Diversified Trajectories}

Our empirical findings illustrate that street vending is animated by young people of diversified profiles where real street entrepreneurs sometimes emerge in some large Southern Cities (Cross \& Morales, 2007). The first portrait is that of unemployment of young educated females. Their educative levels vary from secondary education to university studies. They are single young mothers, who are mostly cohabitating. More than $25 \%$ of them are divorced. The second portrait is that of relatively well-educated young men acting in the street in transition while hoping to get decent jobs. The third portrait is that of adult men and women relatively stabilised in their street activities. Their experience goes beyond 10 years and they do not have other ambitions than to practise and prosper where they are. They constitute almost half of the street vendors.

The biographies show that the most common reasons that pushed them into their nowadays street vending activities are: school dropouts due to lack of financial means to pay tuition fees or frustrating academic failures, jobs losses, death/decline of sponsors, easy gain so as to overcome life harshness, indigence (Mat interview 12/04/2016). Later on, street vendors forge their ways either through a sort of accumulation trajectories or bifurcations. However, a good number of them who set up their businesses through street vending could hardly succeed in carrying out daring projects even after decades. This group made up of young mothers and fathers breakthrough by accumulating enough money in order to step into more lucrative or less harsh activities (Basor interview 22/05/2016). Then street vending appears as an energising spring for a numberless "haves not" in need of a springboard for an entrepreneurial take-off. For example, succeeding in gathering a business fund for formal commerce, working hard so as to raise a given amount of money for emigration requirement or gaining access into Professional Training Schools, are current targets. Our findings reveal that many local entrepreneurs were former street vendors (Victor in- 
terview 16/06/2016). Pragmatically, even after having ascended to the entrepreneurship, they either keep on swelling their wealth or still secure jobs for their family youngsters stepping into active life as unemployed school or universities leavers. The dream of following in the footsteps of old billionaires like the late Kadji De Fosso, the late Andre Sohaing, Victor Fotso or the new rich and other Feymen, motivates young street vendors (Mat interview 12/04/2016). However, the majority of street vendors remain poor.

\subsection{International Supply Networks and Local Distribution Circuits}

This subsection considers street vending as "the back-end of international trade" (Brooks, 2012: p. 1). This consideration helps to stretch power relationship from local to global context. Hardware and second-hand clothes provide an example of integration in the Global Production Network. The local importer ensures the entry of the product into the national territory and this is distributed to the other Regions (Figure 4(a)). For second-hand clothes trade (Figure 4(b)), local

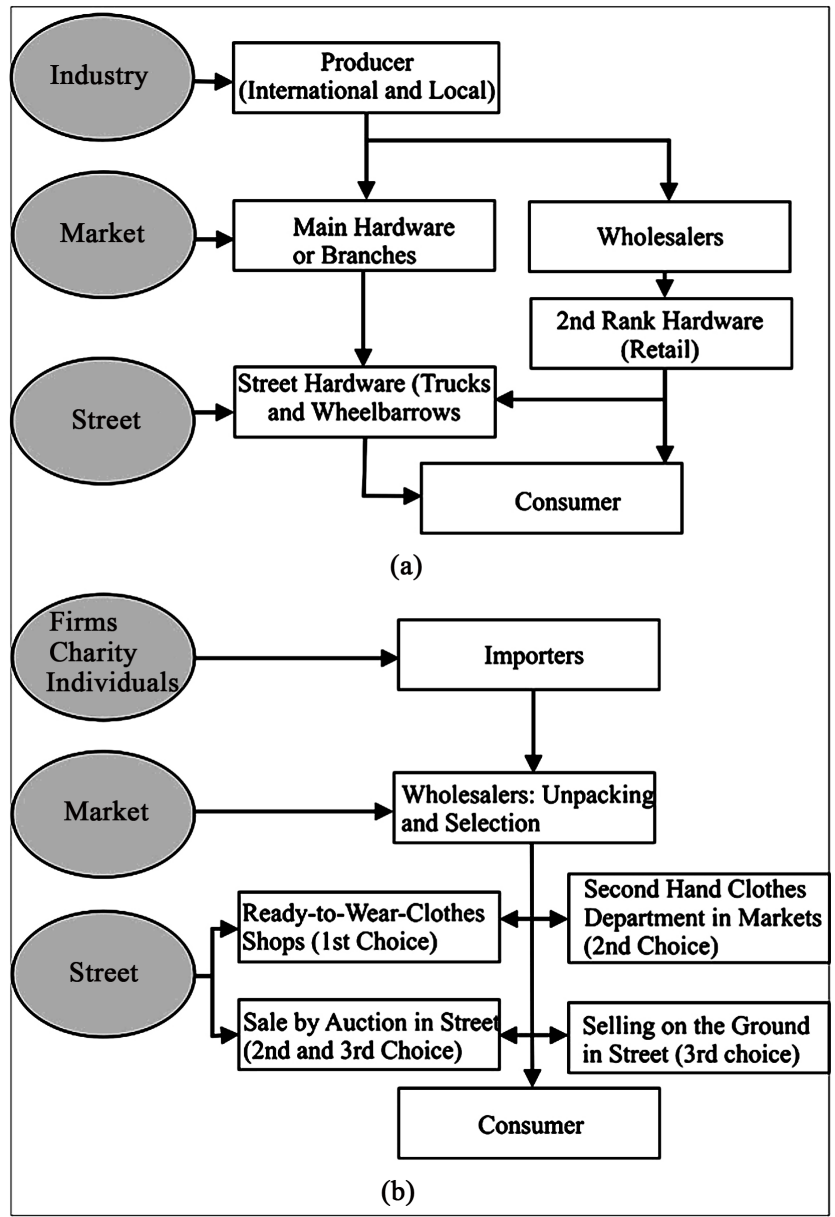

Figure 4. Networks, street hardware and second hand clothes actors. (a) Street hardware network in Bafoussam; (b) Street second hand clothes in Bafoussam. Source: Author, from Fieldwork, 2017. 
importers collect (from individuals, charity organisations and commercial recycler), sort and grade used clothes from developed countries, and transfer them directly to the wholesalers (Brooks 2012). The sorting is directly done during the unpacking and everyone chooses the products according to his/her target in the street. The hierarchy of such product choices (1st, 2nd, 3rd) determines the quality and the nature of the sales stand. As from the 3rd choice, the selling is done directly on the ground.

Wholesalers organised production, exportation and finally structure territories and power relationships at each scale till the street. Maldonado et al. (Maldonado, 1999; Maldonado \& Gaufryau, 2001) and Komi (2011) argued that the informal sector in Africa makes the economy. Therefore, behind each street activity, there is a structure, a chain value or a network of active suppliers ensuring the perennity of street products from global to local (Figure 4). How then, does the supplying circuit which brings those products to the street function? What are the relationships between street vendors and their suppliers?

The supply networks of street vending depend on the origins of the sold products. These products are therefore grouped into three categories: imported manufactured products, locally manufactured and agricultural products, and local services.

- Imported manufactured products are products sold on the street and are delivered by a wholesaler or semi-wholesaler installed in a conventional retail space in Bafoussam. Each wholesaler has his/her forwarders, i.e., his retailers on the street. The goods are delivered to the vendors on the basis of the commercial or familial relationship which links them. Subject to these relationships, goods are either delivered on credit or partially paid. This is a sort of fidelity alliance ensuring the control by the wholesaler over the street retailer. Some would talk about the exploitation of street vendors by wholesalers, but however, this is not the case. It is more a question of loyalty in the commercial relationship. Moreover, frequent fluctuations of market prices often raise doubts as concerning street vendors. Nevertheless, this is an issue of interest in which stakeholders constantly play to gain margins for both. Fieldwork results reveal that the distribution network of imported manufactured products is highly structured with exclusive distributors either on the whole territorial scale or by Regions. Hence, it is possible to better manage the network and to easily follow it to the street as Racaud (2015) argues, citing Chinese plastic products diffusion in Cameroon as an example. During the investigation, a networking system did not emerge to directly protect the street vendors, but rather interpersonal relationships designed to maintain the commercial relationship. An association of Cameroonian vendors exists, but its sporadic actions are limited only to metropolises.

- Manufactured and agricultural local products are processed by local Companies, but the distribution network is less structured and the street vendor can directly buy from the enterprises. On the one hand, bakeries, brewery com- 
panies, oil and soap factories take into consideration more the levels of demand than the organisation of the distribution network. On the other hand, the distribution of local food products shows only illicit and occasional structured organisations. With their associations within vending spaces, the Buyam-Sellam constitutes the most structured and formalised supply network. They prefer to be connected directly to peasants-providers rather than to wholesalers. The National Coordination of Buyam-Sellam intervenes at the level of public policies as a pressure group to facilitate transportation, storage, and relief of fiscal and administrative pressure.

- As for local services like repair, workshops, gaming or telephone booths, transportation of goods and commodities, the nature of the activity gives right to temporary occupation of the public space. This right gives way to permanent or occasional abuses, which administrative authorities struggle to eliminate. Globally, agents and retailers are mutually in conflict for the negotiation of re-localisation operations, just as Municipal Agents protect their clients from the overlapping of authorised limits. For example, the segment around BIAO Roundabout-Total d'en bas Junction is known to be intractable precisely because of the complicity between Police Office and vendors. The influence of the company gives more protection to the service provider in the street. Therefore, hardly will the Municipality abuse stands of multinational corporations like PMUC, Orange or MTN, meanwhile hardly are these major groups accomplices of the activities of its service provider. This rising of formal enterprises in street customers capture strategies is a growing phenomenon in the southern cities, well taken up by Monnet (2006: p. 100) and which testifies to the fact that the street vending tends to be generalised into becoming an urban way of life.

This networking appears to be a vendors' strategy in making use of the social, economic and administrative positions of their relatives to ensure their protection and influence when necessary. Apart from the territorial scale, it recalls forthwith the West African business network as studied by Walther (2015). However, the associations are not strong enough to negotiate with Public Authorities as compared to those in East African Cities (Brown et al., 2010). Sponsorship defines the relationship between the vendor, the wholesaler and the Security Officer. Wholesalers therefore hold retailers in a captive strategy in order to better consolidate their distribution network. In addition, the ethnical and familial approach of sponsorship is more frequent than the professional associative approach. In order to encourage competition and enhance the activity, sponsors at all levels are needed.

Empirical evidence also shows that majority of street vendors about $74 \%$ do not have permanent networks to count on. As a result, street vendor often connect to networks based on problems encountered at a specific moment. A vendor can therefore cease to be a member when the problem has been solved. This, however, depends on the stakes and conditions of the membership. For example, 
membership involves overhead costs that the street vendor cannot afford at all times. The networks that street vendors frequently declare are consolidated family, friendly or corporate networks. According to them, occasional/non-permanent networks are not considered. In view of the fact that street vending is well structured and composed of dynamic young people functioning in a system of network supply, governance issues tend to be complex and socio-politically sensitive.

\section{From Power Relationship to Power Sharing in the Governance of Public Spaces}

\subsection{Infringement of the Street Vending Operating Rules}

This subsection shows that street vendors constantly violate operating rules, either exploiting their relationships and networks mentioned above, or relying on the administrative tolerance. As will follow, street vendors operate at the interstices of formality as Monnet (2006: p. 103) has so well demonstrated. The operating rules of street vending are essentially related to the relationship with taxation and respect for the shared management of the public space. All street vendors are required to pay for Temporary Occupation of the Public Space (TOPS). It is therefore the first administrative and fiscal recognition of the presence of any activity on the street. A square metre of occupied street varies from 200 to 500 F CFA/day depending on the centrality of the area. For example, spaces around BIAO Roundabout and Total d'en bas are among the areas where the TOPS are higher. In addition, the occupation fee is conditioned by a market ticket that costs between $100-200$ F CFA/day and is to be paid to the Municipality. Based on the capital invested, measurable by the estimated value of the goods exposed, the Tax Officer assigns the street vendor to the tax-free regime varying from 6000 to $75,000 \mathrm{~F}$ CFA every three months. For the others, specific rules for the exercise of the activity are involved. For example, health taxes that vary between 3000 and 25,000 F CFA/year are required to contribute to the sanitation of spaces for mass catering known as tournedos.

According to the Technical Services of the City Council, more than $60 \%$ of street vendors pay the TOPS and only $20 \%$ pay another tax beyond, which includes ticket sales, tax-free regime, etc. Street vendors acknowledged that at least half of them do not pay their taxes. For them, the TOPS is sufficient because they struggle to survive. This situation reinforces the position of Municipal Officers to conduct permanent controls over street vendors to optimise tax revenues. However, the Government Delegate is not in favour of a forceful solution that could ignite the social bomb in such a fragile and sensitive sector. According to him, taking street vendors as friends is rather a political asset (Interview conducted on 20/06/2016).

With regards to compliance with standards and quality, the decentralised services of the ministries in charge of these issues are competent to act but they rely 
on the Police. However, street vendors are barely aware of their supervisory role as revealed by a vendor who has been in the business for a long time: "I experienced one or two checks for the past five years" (Bruno, 14th of May 2016). Fieldwork observations reveal that regular interventions in street vending activity are very sensitive and each local authority approaches them with care. It can therefore be argued that street vendors have a lot of power in relation to public space management and urban disorder that they orchestrate as it produces a new spatial and functional organisation of the City.

\subsection{Conquest of Spaces and Public Space Control by Street Vendors}

The conquest of space is a typical manifestation of the power held by street vendors in Bafoussam. It is indeed a takeover of spatial interstices according to Monnet's (2006: p. 103) framework. This conquest of spaces is established through access, location and vending within a portion of the street. The establishment of a business is done by double renting, firstly from the owners of the space adjacent to the street, and secondly from the City Council. It can also be done by simply occupying an unoccupied portion of the public space. The conquest of spaces for an activity therefore consists of identifying and possessing the better positions to easily attract the attention of customers. For a fixed portion, the product exhibition form is permanently renovated whereas for mobile installations, the street is gradually closed until after peak periods. This causes congestion among vendors, pedestrians and vehicles. The flow of cars around strategic locations such as BIAO Roundabout, Total d'en bas between 08:00 am 10:00 am and 5:00 pm - 7:00 pm, for example, is very difficult because street vendors have taken possession of the street with stalls on the ground (Figure 3(a)). Furthermore, between 7:00 pm - 10:00 pm, major junctions and bakeries give a new decor to street vending. The sale of fruits and vegetables, for instance, is combined with the sale of second hand-clothes and utensils (Figure 3(c)). From this perspective, we realise that street vendors gain control when they manage to create favourable conditions by deviating the path of motorists and other passers-by. It is to caution those who do not need street products at that moment to avoid such roads in Bafoussam since thieves and bullies are frequent during peak hours. Thieves prefer peak periods because they can operate freely, skilfully dictating their roles through codes and signs understood only by their accomplices. These routes can only be freely accessed during peak periods by secured convoys and motorists. This is another scenario of power relationships that calls for a shift to power sharing with Public Authorities.

\section{Governance Strategies and Power Sharing}

This subsection further demonstrates the problem of governance that drives the development of street vending in Medium-Sized Cities in the South. Behind the 
contrast of the fight against "urban disorder" is a sharing of public space management with vendors. This is either because vendors have a power that can challenge at certain moment, the managing powers or because tolerance has become a laxity. Special Units of Municipal Police popularly called awaara have been created to restore order, thus, affirming the authority of the Municipality in collecting taxes. Nevertheless, only displacement operations aimed at ensuring a tolerable threshold of street vending are carried out weekly. Exceptional displacement operations respond to obscured motives either for political, fiscal or private interests. A typical example was a raid that happened around BIAO roundabout when the wife of a Municipal Authority was duped of her valuables when she bought some toys during the Christmas period of 2016. In addition, when high ranking State Authorities visit the city, street vendors are displaced as part of beautification operations.

The governance balance sheet in the sector of street vending is finally mitigated. This is because the rate of "disorder" evolves as years go by. However, 'urban disorder' depends on the time and absence of Municipal Guards in the street and also for political convenience. In reality, the political opportunity defines the threshold of pressure that technical units, in these circumstances, the Municipal Police and other Security Units, can exert on street activities. Street vendors are highly sensitive targets and at the same time electoral potential that need to be cautiously managed. This is because they could join the Opposition Parties and complicate the management of the City. A classic example was the case in the 1990s, when the Opposition Party dominated the Municipal Council, thus making the ruling government to lose authority over its former stronghold to the Opposition. Bafoussam is also a commercial City, obtaining up to $80 \%$ of its revenues from commerce (formal and informal) according to reports from the City Council Financial Services. This is one of the reasons why the plight of street vendors is treated with a lot of caution within the public-private dialogue platforms. This regulatory platform is also a strong recommendation from the Association of Mayors to prevent all socio-political agitations emanating from the fight against urban disorder.

The fight against the anarchical occupation of the public space is complex. During peak periods for example, personnel and logistics are insufficient. Interview with the Government Delegate (20/06/2016) reveal that socio-political parameters should be taken into consideration. This is because public spaces have been appropriated by street vendors who build up their own codes and negotiate with the Authority that feels obliged to compromise on the local government prerogatives according to socio-political issues which can become destructive for its own system. The informal sector is deeply rooted in the public sector in African Cities. This assertion, as noted by Paratian and Dasgupta (2005) and OECD (2013) is premised on the basis that all the actors should be protected while the quality and hygienic condition of all products are ensured. 


\section{Discussion}

\subsection{Mapping Street Vending and Understanding Power Relationship and Sharing within Global-local Context in Medium-Sized Cities in Africa}

Monnet's framework test in Mexico, San Salvador, Lima, Rio de Janeiro, adopted in this paper helps to characterise street vending within formal, spatial and mobility dimension. It allows to demonstrate that it is the globalisation window for the poor (Choplin \& Pliez, 2015, 2018), because it is the single forum where they could interact with the new commodities of the world's economy. By analysing the relation of street vending to major urban changes, the Monnet hypothesis (p100) is based on the fact that the intensification of urban mobility increases the demand for certain products in circulation spaces. He believes that streets once again, are becoming living spaces as it was the case in medieval cities and express dysfunctions of functionalistic urbanism hardly considered by urban governance systems. The demand for governance is necessary as city dwellers under the pressure of daily mobility find it a pleasure to get the basics needs on their way as soon as they need it. The Monnet's framework thus makes it possible to understand that street vending exploits the "in-between spaces", referred to as "socio-spatial interstices" (p. 103) to settle because they has become privileged contact spaces with constantly mobile customers. The administrative and social tolerance finally gives a bargaining power to street vendors, a power that asserts itself in the organisation and the tacit functioning of the commercial streets in Bafoussam, which derives its source from the proximity, the direct contact between vendors and customers in Medium-Sized Cities of the South. It is therefore a suitable framework for Medium-Sized Cities where circulation spaces are multifunctional, i.e. at the same time social, commercial and political spaces. Nevertheless, the Monnet's framework does not allow analysis of the formal and informal, local and international networks that underlie street vending and ensure its perennity in making it a way of live in Medium-Sized Cities. This is where the GPN get interesting approaches to understand street vendors' supplier networks and establish an appropriate system of governance.

GPN approach of a street vending products (Brooks, 2012) help to complete Monnet's framework so as to identify and understand the socio-spatial embeddedness of power relationships among different actors. As street vending is a matter of network that spreads and gains territories at different scales, working at the end node of the said network is quite restrictive, although it ought to be underlined by actors' base connection in globalised economy within which poor people in the South are completely engaged (Choplin \& Pliez, 2018). As it is the case here, street vendors are human spreaders of globalisation in rural areas as well as in small and medium-sized Cities. This role is quite minimised in literature.

A nonlinear continuum exists between the wide spectrum of the distribution network right from wholesalers up to street vendors. The case of Bafoussam 
shows that the end node distribution network is based more on powerful social relationships than on economic spider web scope. Urban elites and great business people are not against street vending as it had been mentioned by Bromley (2000), but rather against non-integrated networks as Brooks (2012) duly stated, because they do stand out of the sphere of assured control. Then, as this empirical case study entails, the socio-political embeddedness of the informal sector revitalises its strength. The quality of street products is always questionable (Abimbola, 2012) as most of the street vendors are not undoubtedly, able to provide the source of their goods. So, only wholesalers can trustfully certify the quality of their merchandises by releasing at will the channels leading to the acquisition of good quality items: succeeding in tying a cooperation with terms that becomes a real privilege, indeed!

\subsection{Future of Street Vending and Governance of Medium-Sized Cities in Africa}

As the socioeconomic and political context of African Countries is fragile, informal economy thus has to prosper especially in rural areas and in Intermediate Cities so as to boost global informal economy. The case of Bafoussam and most African Cities (Brown, 2006; Brown et al., 2010) show that contested spaces and finally power sharing are not only a debate of urban development but a global stake between formal and informal. The constant recycling of the informal sector within the African economy makes us think that conflicts with local governments are only a fight for an equilibrium from which high and low incomes groups can live together while sharing global commodities (Hughes \& Reimer, 2004; Berndt \& Boeckler, 2009). This could be part of rights-based approaches proposed by Brown (2017) as a new framework to cope with actual challenges of informal economy. This is necessary as in line with Monnet (2006), we have found that multinational companies such as telecommunication and mass manufacturing companies are directly engaged in the quest for street customers.

The approach of formal/informal coexistence may be more practical now. Fighting against street vending requires, foremost, a general evolution of all the social groups' living conditions. This is more of a macroeconomic systems concern rather than a simple level of City management. One of the solutions to the questions of opposing interests and the complexity of street vending, for instance, could be to design the sharing of commercial streets to different groups of street vendors and other users of the same public space. However, designing with actual expertise the sharing of commercial streets would consequently require a careful review of traffic codes. The Axis "BIAO" Roundabout-Total d en bas junction during peak periods ought to be the limelight of such a preoccupation. The tacit validation of this urban traffic pattern is a form of spatial and urban mobility planning that relies on sharing power with street vendors. As we have been aware of the importance of street vending and the economic networks it structures, we are more convinced that we can otherwise manage multifarious 
facets of disorder orchestrated in the public space. Since 2000, the City of Nairobi for example has been experimenting an inclusive dialogue between street vendors, local Government and formal businessmen (Kamunyori, 2007; Linehan, 2015; Roever \& Skinner, 2016; Schlegel \& Racaud, 2016). In the Cameroonian context, prospecting must be firstly oriented towards the City Managers and local Government. Urban planning agenda may include streets pedestrians during peak periods and secure junctions where street vendors can freely and fearlessly display their products without any anxiety of Police assaults. Therefore obliging street vendors to organise themselves in ensuring order and safety of users in the areas they competently control, would render them strongly committed to more collaboration. This involves organising street vendors into associations and groups of common interests.

\section{Conclusion}

The present study has shown that street vending is well integrated into urban economic fabric in Medium-Sized Cities in Cameroon. This integration has been done through administrative and social tolerance, i.e. a compromise on the governance of public space. All city dwellers are involved in street vending especially the poor and those who are in a haste. This has been explained by the fact that the street is no longer just a circulation space, but a living space where the city dwellers while circulating, can get some basic needs as Monnet (2006) stated. This situation was imposed according to the socio-economic situation of the African countries. The informal economy thus has the power to generate networks that transform people, spaces and the management of the city.

With regard to the power of transforming people, street vending has positive and negative aspects for vendors and their customers. Some street vendors' biographies in Bafoussam show that their temporary activity is a step forward to the moulding of future experienced local entrepreneurs. Nonetheless, these biographies sufficiently reveal some unbefitting misdeeds as regards the socio-economic behaviour of the concerned development actors: culture of violence, antisocial behaviour, corruption, etc. All these aspects form an environment into which street vendors grow. This form of socialisation from the street indifferently involves young people from all kinds of backgrounds. Customers also have diversified experiences that determine their total or partial support, for example, the experience of poor quality (partial support) or low prices (total support).

Looking at the power of transforming spaces, it is demonstrated that buying on the street is part of African urbanity, especially in Medium-Sized Cities in Africa where it is often the only window to display commodities. Street vending is more a solution than a problem to mass distribution. This explains why eviction solutions do not work and why considering street vending as an urban disorder is a misjudgement. It is observed that African urbanity is accommodating to spaces which integrate all urban functions.

As this is understood, it is now clear that power relationship held by street 
vending becomes a power sharing concerning the governance of public spaces. This case study has shown that through infringement of the street vending operating rules and public space control, street vendors demonstrate their power relationship and sharing. The flexibility of the choices of struggle precisely translates the dilemma and even the temperate strategy deployed by Bafoussam Public Authorities vis-à-vis such a fragile socio-economic system of a specific layer of city development actors. The magnitude of efforts likely to ensure order in the city takes into consideration the sensitive nature of street vendors and consequently avoids turbulent circumstances which might degenerate into the destabilisation of the system, namely social explosion, deterioration of networks and relationships with donors, etc. This validates the hypothesis that due to such flexibility and tolerance, street vendors power relationships have shifted to power sharing in the governance of public spaces in Bafoussam.

\section{Conflicts of Interest}

The author declares no conflicts of interest regarding the publication of this paper.

\section{References}

Abimbola, O. (2012). The International Trade in Second-Hand Clothing: Managing Information Asymmetry between West African and British Traders. Textile: The Journal of Cloth and Culture, 10, 184-199. https://doi.org/10.2752/175183512X13315695424310

Assako, R. J. (2012). A propos de l'opération d'embellissement de Yaoundé, capitale d'Afrique centrale. Les Cahiers d'Outre-Mer, 259, 371-393. https://doi.org/10.4000/com.6652

Augustin, J. P. (2002). Espaces publics et villes d'Afrique noire. Géographie et cultures, 41, 3-9.

Berndt, C., \& Boeckler, M. (2009). Geographies of Exchange and Circulation I: Constructions of Markets. Progress in Human Geography, 33, 535-551. https://doi.org/10.1177/0309132509104805

Bromley, R. (2000). Street Vending and Public Policy: A Global Review. International Journal of Sociology and Social Policy, 20, 1-29. https://doi.org/10.1108/01443330010789052

Brooks, A. (2012). Stretching Global Production Networks: The International Second-Hand Clothing Trade. Geoforum, 44, 10-22. https://doi.org/10.1016/j.geoforum.2012.06.004

Brown, A. (Eds.). (2006). Contested Space: Street Trading, Public Space and Livelihoods in Developing Cities. Rugby: ITDG Publishing. https://doi.org/10.3362/9781780444703

Brown, A. (Eds.). (2017). Rebel Streets and the Informal Economy, Street Trade and the Law. London: Routledge.

Brown, A., Lyons, M., \& Dankoco, I. (2010). Street Traders and the Emerging Spaces for Urban Voice and Citizenship in African Cities. Urban Studies, 47, 666-683. https://doi.org/10.1177/0042098009351187

Choplin, A., \& Pliez, O. (2015). The Inconspicuous Spaces of Globalization, Articulo-Journal of Urban Research, 12. http://journals.openedition.org/articulo/2905 
Choplin, A., \& Pliez, O. (2018). La mondialisation des pauvres, Loin de Wall Street et de Davos. Seuil: La République des Idées.

Coe, N. M., Dicken, P., \& Hess, M. (2008). Global Production Networks: Realizing the Potential. Journal of Economic Geography, 8, 271-295. https://doi.org/10.1093/jeg/lbn002

Cross, J. C. (1998). Informal Politics: Street Vendors and the State in Mexico City. Stanford: Stanford University Press.

Cross, J. C., \& Morales, A. (2007). Street Entrepreneurs: People, Places and Politics in Local and Global Perspective. London and New York: Routledge.

Etoughe-Efe, J. E. (2010). La restauration informelle en Afrique subsaharienne. Paris: L'Harmattan.

Fleury, A. (2004). La rue: Un objet géographique? Tracés. Revue de Sciences Humaines, 5, 33-44. http://traces.revues.org/3133

Githiri, G., Ngugi, R., Njoroge, P., \& Sverdlik, A. (2016). Nourishing Livelihoods. Recognising and Supporting Food Vendors in Nairobi's Informal Settlements. IIED Working Paper, London: International Institute for Environment and Development (IIED).

Henderson, J., Dicken, P., Hess, M., Coe, N., \& Wai-Chung, Y. (2002). Global Production Networks and the Analysis of Economic Development. Review of International Political Economy, 9, 436-464. https://doi.org/10.1080/09692290210150842

Hughes, A., \& Reimer, S. (Eds.) (2004). Geographies of Commodity Chains. London: Routledge. https://doi.org/10.4324/9780203448694

Indovina, F. (2016). Urban Disorder and Vitality. City, Territory and Architecture, 3, 18. https://doi.org/10.1186/s40410-016-0048-7

Kamunyori, S. W. (2007). A Growing Space for Dialogue: The Case of Street Vending in Nairobi's Central Business District. Unpublished Master Thesis, Cambridge, MA: Massachusetts Institute of Technology. https://dspace.mit.edu/handle/1721.1/40123

Komi, D. (2011). L'économie informelle en Afrique subsaharienne. Paris: L'Harmattan.

Lamblin V., \& Massot, M. H. (2011). Prospective de la mobilité dans les villes moyennes. Rapport final de l'étude de Futuribles International. Paris: Futuribles International.

Linehan, D. (2015). Nairobi: Markets without Walls. Cork: University College Cork.

Maldonado, C. (Dir.) (1999). Le secteur informel en Afrique face aux contraintes légales et institutionnelles. Genève: BIT.

Maldonado, C., \& Gaufryau, B. (Dir.) (2001). L'économie informelle en Afrique francophone. Structure, dynamiques et politiques. Genève: BIT.

Mitullah, V. (2003). Street Vending in African Cities: A Synthesis of Empirical Findings from Kenya, Cote d'Ivoire, Ghana, Zimbabwe, Uganda and South Africa. WIEGO Urban Policies.

http://www.wiego.org/sites/default/files/publications/files/Mitullah_Streetvending_Afri can_Cities.pdf

Monnet, J. (2006). Le commerce de rue, ambulant ou informel et ses rapports avec la métropolisation: une ébauche de modélisation. Autrepart, 39, 93-109.

OECD (2013). Settlement, Market and Food Security. Paris: OECD Publishing. https://doi.org/10.1787/9789264187443-en

Paratian, R., \& Dasgupta, S. (2005). Confronting Economic Insecurity in Africa. Geneva: International Labor Office (ILO) Publishing.

Racaud, S. (2015). Chasing a Pair of Chinese Sandals: Markets and Trade Routes in Cam- 
eroon. Articulo-Journal of Urban Research, 12. http://articulo.revues.org/2899

Roever, S. (2014). Informal Economy Monitoring Study Sector Report: Street Vendors. Cambridge, MA: WIEGO.

http://wiego.org/sites/wiego.org/files/publications/files/IEMS-Sector-Full-Report-Stree t-Vendors.pdf

Roever, S., \& Skinner, C. (2016). Street Vendors and Cities, Environment \& Urbanization. International Institute for Environment and Development (IIED).

Sampson, R. J. (2009). Disparity and Diversity in the Contemporary City: Social (Dis)Order Revisited. The British Journal of Sociology, 60, 1-31. https://doi.org/10.1111/j.1468-4446.2009.01211.x

Schlegel, P., \& Racaud, R. (2016). Urbanization and Street Vending. How Street Vending, an Individual and a Collective Resource, Can Be Integrated into the Urban Governance? Report, Nairobi: IFRA.

Sohel, A., Simiyu, E., Githiri, G., Sverdlik, A., \& Mbaka, S. (2015). Cooking up a Storm. Community-Led Mapping and Advocacy with Food Vendors in Nairobi's Informal Settlements. IIED Working Paper, London: International Institute for Environment and Development (IIED).

Staudt, K. (1996). Struggles in Urban Space: Street Vendors in El Paso and Ciudad Juárez. Urban Affairs Review, 31, 435-454. https://doi.org/10.1177/107808749603100401

Steck, J. F. (2006). La rue africaine, territoire de l'informel? Flux, 4, 73-86. https://doi.org/10.3917/flux.066.0073

Walther, O. (2015). Social Network Analysis and Informal Trade. Sønderborg, Department of Border Region Studies, Working Papers 1.

https://doi.org/10.2139/ssrn.2593021 